\title{
Canonical Correlation Analysis to Study the Impacts of Different Social Factors on Level of BMI and Prevalence of Diabetes Among Children and Adolescents of Some Affluent Families
}

\begin{abstract}
K.C. Bhuyan*1, A.F. Urmi ${ }^{2}$
Professor [Retired] of Statistics, Jahangirngar University, Bangladesh. Lecturer in Statistics, American International University- Bangladesh. kcbhuyan2002@yahoo.com

*Corresponding Author: K.C. Bhuyan, Professor [Retired] of Statistics, Jahangirngar University, Bangladesh.

Abstract

The present analysis was done using the data collected from 662 children observed from 560 randomly selected families of students of American International University - Bangladesh. Among the investigated children and youth 465 were in underweight group. Obesity and severe obesity were observed among 9.1 percent children and adolescents. It was evident that level of obesity and prevalence of diabetes were significantly associated and these two characters were associated with different socioeconomic variables of the parents and of the respondents. Thus canonical correlation analysis was performed to study the complex relations of level of obesity and prevalence of diabetes with other socioeconomic variables. The analysis indicated that important variables for complex relationship of level of BMI and prevalence of diabetes were parents' education, age of children, family income and food habit of the children.
\end{abstract}

\section{INTRODUCTION}

During the past 3 decades, prevalence rates of childhood and adolescence obesity, measured by body mass index (BMI) above the $95^{\text {th }}$ percentile for age and sex, are in increasing trend. The problem of obesity is one of the most important public health issues [WHO 2002]. Again excess body weight is the sixth most important risk factor contributing to the overall burden of disease worldwide. Around 110 million children are now classified as overweight or obese [1]. Approximately, 43 million pre-school aged children throughout the world have been estimated to be overweight [2] and 92 million are considered to be at risk of overweight. In Bangladesh, overweight and obesity are in increasing trend and prevalence of these range from $1 \%$ to $17.9 \%$ with higher percentage among urban children across different age groups and sexes [3]. The increasing prevalence of overweight and obesity among children (0-12years) and adolescents (13-19 years) has emerged as a major public health threat in Bangladesh [4].
Obesity is associated with significant health problem in the pediatric age group and is an important early risk factor for much of adult morbidity and mortality [5]. The problems of obesity among children and youth are manifold. Some of these are (i) health problem, (ii) insulin sensitivity, (iii) abdominal abnormality, (iv) epidemiology, (v) environmental risk, (vi) social change, (vii) cardiovascular abnormalities, (viii) psychological abnormalities etc.

Obesity is associated with significant health problem in the pediatric age group and is an important early risk factor for much of adult morbidity and mortality $[5,6,7,8,9]$. Childhood obesity frequently persists into adulthood, and up to $80 \%$ of the obese children reported to become obese adults [10]. Many of the metabolic and cardiovascular complications of obesity are already present during childhood and are closely related to the presence of insulin resistance, the most common abnormality of obesity [11]. In some study $[12,13]$ it was mentioned that insulin resistance might be a result of the imbalance of fat distribution in both 
Canonical Correlation Analysis to Study the Impacts of Different Social Factors on Level of BMI and Prevalence of Diabetes Among Children and Adolescents of Some Affluent Families

the abdominal fat depot and skeletal muscle tissue of youth. The most common medical morbidities associated with obesity include metabolic risk factors for type II diabetes including high blood pressure, high cholesterol, impaired glucose tolerance and metabolic syndrome $[14,15]$. Behavioral factors have significant effects on metabolic risk. It had been observed in some research findings that youth who do not meet guidelines for dietary behavior, physical activity and sedentary behavior have greater insulin resistance than those who do meet guidelines [16].

Psychological abnormalities are closely associated with obesity in children and youth. Obesity in youth may be associated with later depression in childhood [17].

In addition, abdominal obesity seems to be strongly associated with concomitant depression in males. Female obese as adolescents may be at increased risk for development of depression or anxiety disorders.

Environmental risk factors for overweight and obesity are very strong and inter-related. Sub optimal cognitive stimulation at home and poor socio-economic status predict development of obesity [18]. Parental food choice significantly modify child food preferences[19]. Children and adolescents of poor socio-economic status tends to consume less quantities of fruits and vegetables and to have a higher intake of total and saturated fat $[20,21]$.

Early rebound of BMI is linked to glucose intolerance and diabetes in adults [22]. Short sleep duration in children is also associated with an increase in the odds of becoming obese as well as increase in body fat percent [23].

The childhood obesity has significant impact on dramatic and rapid changes in the society. It is evident that individual's eating and physical activity behaviors are heavily influenced by surrounding social and physical environment contexts both for adults and children [24]. Urbanization related intake behaviors that have shown to promote obesity include frequent consumption of meals at fast food shop $[25,26]$ which is, in most cases, high calorie food containing high level of fat and low level of fiber. The intake of sweetened beverage from fast food shops also promotes obesity [24]. The behavior of food intake are cultivated in an environment in which high calorie food is abundant, affordable to children of affluent families, available and easy to consume with minimal preparation as is the case of urban cities throughout the country.

Low level of physical activity is definitely promoted by an automated and automobile oriented environment that is conductive to a sedentary lifestyle [27]. The level of obesity and hence the prevalence of diabetes may increase in the urban area if there is no scope of safe walkways, playgrounds and other avenues for physical activity related to recreation [24].

From the above discussion, it can be concluded that growing level of obesity among children and youth and increasing the rate of prevalence of diabetes are of great concern throughout the world. Many of the complications are silent and often go undiagnosed. The obese children are at high risk for the development of early morbidity.

Considering all these aspects discussed above, the objective of the study was planned to study the joint relationship of level of obesity and prevalence of diabetes with other socio-economic factors which were more responsible for the variation in the level of obesity among children and adolescents under 18 years of age coming out from affluent families. The specific objectives were:

i). To investigate the complex relationship of two sets of variables, one was dependent set and another was explanatory set. The level of obesity and prevalence of diabetes were in dependent set and some socioeconomic variables were in explanatory set.

ii). To identify the mostimportantexplanatoryvariables responsible for both the dependent variables.

These objectives can be fulfilled by doing canonical correlation analysis [ 28,29,30].

\section{METHODOLOGY}

The present analysis was based on 662 responses observed from 560 randomly selected affluent $[31,32]$ families of students of American International University - Bangladesh during Summer 2016-17 semester. During the semester there were 9488 students in the university. One of our objective was to estimate the proportions of children and youth of different levels of obesity along with a combined proportion of obese and severe obese group of all ages of children and youth. In a previous study [4] it was reported that there were $7 \%$ overweight and 
Canonical Correlation Analysis to Study the Impacts of Different Social Factors on Level of BMI and Prevalence of Diabetes Among Children and Adolescents of Some Affluent Families

obese children and youth in Bangladesh. Accordingly, we had decided to have a proportion of at least $7 \%$ overweight and obese children and youth with margin of error of $2 \%$ with $95 \%$ confidence in our study. To have such an estimate it required a sample of students of size $n$, where $n=625$ [proportion of expected obese and overweight children and youth, $\mathrm{p}=0.07, \mathrm{q}=0.93$, margin of error, $d=0.02$, normal ordinate for $95 \%$ confidence, $\mathrm{z}=1.96]$. This sample size covered $6.6 \%$ students of the university. The sample students were selected by simple random sampling method and were expecting at least responses from $5 \%$ families of the students. However, information were received from 560 families, covering the data of 662 children.

The data were collected through pre-designed and pre-tested printed questionnaire covering the questions related to the demographic characteristics of the children and youth of age below 18 years and the questions related to the socioeconomic variables of the parents. The randomly selected students were given written instructions how to collect information and they were requested to help in collecting information from their parents, who were very much concerned about the health hazard of their offspring. The children's fathers / mothers filled in the questionnaires as they were under 18 years of age and some were even below 10 years. The important collected information were age, height, weight, sex, food habit, time spent, involvement in co-curricular activities, if it is feasible, of the children. To study the socioeconomic background of the children, the information regarding parent's level of education, occupation and income were also collected. For youth having diabetes, the latest blood sugar level measured by registered practitioner or measured in a registered clinic also recorded. Association of level of obesity of offspring with families' socioeconomic back ground were examined using chi-square test, where significant association was concluded when p-value $\leq 0.05$. For canonical correlation the variables used were residence of respondents, their age, value of BMI, utilization of time, prevalence of diabetes among them, parents' education, occupation and income. Some of the variables were qualitative in character. These variables were transformed to nominal measures by assigning numbers.

For canonical correlation analysis the variables level of BMI and prevalence of diabetes were considered dependent set [ Y - Set ] and the variables residence, parents' education, occupation, family income, respondents' age, food habit and time spent were considered as explanatory set [X-set ].

Let $R_{x x^{\prime}}, R_{y y}$ and $R_{x y}$ be the sample correlation matrices of the variables in X-set,Y-set and in both X-set and Y-set, respectively. According to the objective of the study, it is needed to find $Y^{*}=\bar{b} Y$ and $X^{*}=a$ a, two liner combinations of the variables in Y-set and X-set, respectively, so that the simple correlation coefficient of $\mathrm{X}^{*}$ and $\mathrm{Y}^{*}$ becomes maximum, where $\mathrm{a}$ and $\mathrm{b}$ are eigen values of the characteristic equations

$\left(R_{x x}{ }^{-1} R_{x y} R_{y y}{ }^{-1} R_{y x}-\lambda I\right) a=0$
$\left(R_{y y}{ }^{-1} R_{y x} R_{x x}{ }^{-1} R_{x y}-\lambda I\right) b=0$

Here the elements in a and $b$ are the canonical weights, the magnitude of which indicates the importance of the variables in X-set and Y-set, respectively to show the maximum correlation between the variables in both sets. The canonical correlation analysis is fruitful if the variables in X-set and Y-set are significantly correlated. This can be done by the test statistic

$\left.\chi^{2}=-(\mathrm{n}-1)-1 / 2(\mathrm{p}+\mathrm{q}+1)\right) \ln \Lambda$, where

$\Lambda=\prod_{j=1}^{M}\left(1-\lambda_{j}\right), \lambda_{j}$ are the eigen values of characteristic equations given above; $p$ and $q$ are the number of variables in Y-set, $(p=2)$ and $X$-set $(q=9)$, respectively. The number of $\lambda j^{\prime}$ s is $M=\min (p, q)$. This $\chi^{2}$ has pqd.f. The rejection of $\mathrm{H}_{\mathrm{o}}: \Sigma_{\mathrm{xy}}=0$ against

$\mathrm{H}_{\mathrm{A}}: \sum_{\mathrm{xy}} \neq 0$ by the above $\chi^{2}$-test statistic justifies the fruitful canonical correlation analysis.

From the analysis, number of canonical variable pairs are min (p, q). But all the pairs may not be statistically significant. The significance of $j$-th canonical variate pair is tested by the statistic.

$\chi^{2}=-((n-1)-1 / 2(p+q+1)) \ln \Lambda^{*}$, where

$\Lambda^{*}=\prod_{j^{\prime}=M^{\prime}}^{M}\left(1-\lambda_{j}\right), \mathrm{M}^{\prime}<\mathrm{M}$

This $\chi^{2}$ has $\left(p-M^{\prime}\right)\left(q-M^{\prime}\right)$ d.f.

The main objective of the analysis is to study the relationship of any variable in Y-set with any variable in X-set. The amount of relationship can be measured by calculating cross-weights, where the cross-weight is the product of canonical loadings of any variable and canonical correlation coefficient. For j-th canonical variate pair is the canonical correlation coefficient and $\mathrm{R}_{\mathrm{xx}(\mathrm{j})}{ }^{*}=\mathrm{R}_{\mathrm{xx}} \cdot \mathrm{a}_{\mathrm{j}}$ and $\mathrm{R}_{\mathrm{yy}(\mathrm{j})}{ }^{*}=\mathrm{R}_{\mathrm{yy}} \cdot \mathrm{b}_{\mathrm{j}}$

are the canonical loadings of $\mathrm{X}$-set and Y-set, respectively, corresponding to $j$-th canonical variate 
Canonical Correlation Analysis to Study the Impacts of Different Social Factors on Level of BMI and Prevalence of Diabetes Among Children and Adolescents of Some Affluent Families

pair. Here $a_{i}$ and $b_{j}$ are the vectors of canonical weights for $j$-thvariate pair. Each canonical variate pair explains certain percentage of total variation of Y-set and X-set. This can be measured, respectively by

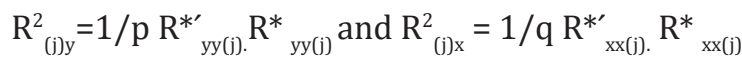

\section{RESULT AND Discussion}

The present analysis was done using the data of social, medical and economic aspects of 662 children of age less than or equal to 18 years investigated from 560 randomly selected families of the students of American International University - Bangladesh. Amongst the studied children 22.8 percent are affected by diabetes. This percentage among the obese and severe obese group of children was 32.2 indicating that level of obesity and prevalence of diabetes was significantly associated [ $\mathrm{c}^{2}=8.741, \mathrm{p}$-value $=0.033$, Table 1 ]. Considering the prevalence of diabetes among the obese and severe obese group compared to nonobese group, the former group were 69 percent more exposed to the problem of diabetes $[0 . R=1.69]$. Their risk ratio was 1.47 compared to non-obese group. Amongst the investigated children 70.2 percent were in underweight group and 9.1 percent were in obese and severe obese group. The level of obesity was measured by the amount of BMI (weight in $\mathrm{kg} /$ height in $\mathrm{m}^{2}$ ). The mean value of BMI was 17.67 with a standard deviation 10.58. The underweight group of children and adolescents had BMI $<23$,. The BMI of other three groups were $23-<30,30-<45$ and $45+$. The levels of BMI were decided according to the percentile values [33]. This findings was almost similar to that observed in another study [4].

Table 1. Distribution of respondents according to level of obesity and prevalence of diabetes

\begin{tabular}{|r|l|l|l|}
\hline Level of obesity & Prevalence of & diabetes & \\
\hline & Yes & No & Total \\
\hline Underweight, $\mathrm{n}$ & 109 & 356 & 465 \\
$\%$ & 23.4 & 76.6 & 70.2 \\
\hline Overweight, $\mathrm{n}$ & 23 & 114 & 137 \\
\hline$\%$ & 16.8 & 83.2 & 20.7 \\
\hline Obese, & 16 & 26 & 42 \\
\hline$\%$ & 38.1 & 61.9 & 6.3 \\
\hline Severe obesity & 3 & 15 & 18 \\
\hline$\%$ & 16.7 & 83.4 & 2.8 \\
\hline $\mathrm{n}$ & 151 & 511 & 662 \\
\hline Total , & 22.8 & 77.2 & 100.0 \\
\hline
\end{tabular}

Amongst the observed children and adolescents 78.1 percent were in the age group 10 years and above and diabetes was prevailed among 24.6 percent of them. With the increase in age prevalence of diabetes was increasing. This is alarming for the parents and for the society though the prevalence was not significantly increased with the age $\left[\left[\chi^{2}=5.351, p\right.\right.$-value $=0.069$, Table 2].

Table 2. Distribution of children and adolescent according to their age and prevalence of diabetes.

\begin{tabular}{|c|c|c|c|c|c|c|}
\hline \multirow{2}{*}{$\begin{array}{l}\text { Age in } \\
\text { years }\end{array}$} & \multicolumn{4}{|c|}{ Prevalence of diabetes } & \multicolumn{2}{|c|}{ Total } \\
\hline & $\begin{array}{l}\text { Yes } \\
\mathrm{n}\end{array}$ & $\%$ & $\begin{array}{l}\text { No } \\
\mathrm{n}\end{array}$ & $\%$ & $n$ & $\%$ \\
\hline$<5$ & 6 & 14.3 & 36 & 85.7 & 42 & 6.3 \\
\hline 5-10 & 18 & 17.5 & 85 & 82.5 & 103 & 15.6 \\
\hline $10+$ & 127 & 24.6 & 390 & 75.4 & 517 & 78.1 \\
\hline Total & 151 & 22.8 & 511 & 77.2 & 662 & 100 \\
\hline
\end{tabular}

It was observed that most ( $72.5 \%$ ) of the investigated children and youth were from urban area and 18.1 percent of them were diabetic. The corresponding percentage among the rural children and youth was 37.8. This differential in prevalence rates of diabetes was significant $\left[\chi^{2}=46.64, p\right.$-value $=0.000$, Table 3$]$. However the odd ratio ( 0.41 ) did not indicate that the urban children were more exposed to prevalence of diabetes compared to non-urban children.

Table 3. Distribution of children and adolescents according to their residence and prevalence of diabetes

\begin{tabular}{|l|l|l|l|l|l|l|}
\hline \multirow{2}{*}{ Residence } & \multicolumn{3}{|l|}{ Prevalence of diabetes } & \multicolumn{2}{l}{ Total } \\
\cline { 2 - 6 } & \multicolumn{2}{|l|l}{$\begin{array}{l}\text { Yes } \\
\mathrm{n}\end{array}$} & \multicolumn{2}{l}{$\begin{array}{l}\text { No } \\
\mathrm{n}\end{array}$} & \multicolumn{2}{|c|}{$\mathrm{n}$} \\
\hline Urban & 87 & 18.1 & 393 & 81.9 & 480 & 72.5 \\
\hline Rural & 45 & 37.8 & 74 & 62.2 & 119 & 18.0 \\
\hline Others & 19 & 30.2 & 44 & 69.8 & 63 & 9.5 \\
\hline Total & 151 & 22.8 & 511 & 77.2 & 662 & 100 \\
\hline
\end{tabular}

The information about the children were collected from the educated families where most of the fathers of the children were higher educated ( $77.9 \%$ ) and 20.3 percent children of these families were affected by diabetes. Prevalence of diabetes of children and youth 
Canonical Correlation Analysis to Study the Impacts of Different Social Factors on Level of BMI and Prevalence of Diabetes Among Children and Adolescents of Some Affluent Families

were significantly associated with father's education $\left[\chi^{2}=46.643\right.$, $p$-value $=0.000$, Table 4 ]. However, there was no evidence that children of higher educated fathers were more exposed to prevalence of diabetes compared to children of less educated fathers [ O.R = $0.56, \mathrm{R} \cdot \mathrm{R}=0.65]$.

Table 4. Distribution of children and adolescents according to their fathers' education and prevalence of diabetes

\begin{tabular}{|c|c|c|c|c|c|c|}
\hline \multirow{3}{*}{$\begin{array}{l}\text { Father's } \\
\text { Education }\end{array}$} & \multicolumn{4}{|c|}{ Prevalence of diabetes } & \multicolumn{2}{|c|}{ Total } \\
\hline & \multicolumn{2}{|l|}{ Yes } & \multicolumn{2}{|l|}{ No } & $n$ & $\%$ \\
\hline & 29 & 63.0 & 17 & 37.0 & 46 & 6.9 \\
\hline Secondary & 17 & 17.3 & 83 & 82.7 & 100 & 15.1 \\
\hline Higher & 105 & 20.3 & 411 & 79.7 & 516 & 77.9 \\
\hline Total & 151 & 22.8 & 511 & 77.2 & 662 & 100 \\
\hline
\end{tabular}

Most of the investigated children were from business families ( $44.6 \%$ ) and servicemen families ( $44.6 \%$ ). Children from families of other profession including agriculture were only 10.8 percent. But higher proportion ( $34.7 \%$ ) of them were affected by diabetes. The differential in rates of prevalence of diabetes of children andyouth of families of different occupations were significant $\left[\chi^{2}=15.783 \mathrm{p}\right.$-value $=0.000$,Table 5]

Table 5. Distribution of children and adolescents according to their fathers' occupation and prevalence of diabetes

\begin{tabular}{|l|l|l|l|l|l|l|}
\hline \multirow{2}{*}{$\begin{array}{l}\text { Father's } \\
\text { Occupation }\end{array}$} & \multicolumn{4}{|l|}{ Prevalence of diabetes } & \multicolumn{2}{l}{ Total } \\
\cline { 2 - 8 } & Yes & \multicolumn{3}{l|}{$\begin{array}{l}\text { No } \\
\mathrm{n}\end{array}$} & \multicolumn{2}{l}{ n } \\
\hline Business & 46 & 15.6 & 249 & 84.4 & 295 & 44.6 \\
\hline Service & 80 & 27.1 & 215 & 72.9 & 295 & 44.6 \\
\hline Others & 25 & 34.7 & 47 & 65.3 & 72 & 10.8 \\
\hline Total & 151 & 22.8 & 511 & 77.2 & 662 & 100 \\
\hline
\end{tabular}

The $0 . R=1.95$ indicated that the children of families of agriculture and other profession were 95 percent more exposed to prevalence of diabetes compared to children of servicemen and businessmen families. Similar findings were also observed in case of mother's education. However, in respect of mothers' education children of higher educated mothers were lesser exposed compared to the children of mothers of other levels of education $\left[0 . R=0.80, \chi^{2}=51.67, p-\right.$ value $=$ 0.000 , Table 6 ].

Table 6. Distribution of children and adolescents according to their mothers' education and prevalence of diabetes

\begin{tabular}{|l|l|l|l|l|l|l|l|}
\hline \multirow{2}{*}{$\begin{array}{l}\text { Mother's } \\
\text { education }\end{array}$} & \multicolumn{4}{|l|}{$\begin{array}{l}\text { Yrevalence of diabetes } \\
\text { Yes }\end{array}$} & \multicolumn{2}{l|}{$\begin{array}{l}\text { No } \\
\text { notal }\end{array}$} & \multicolumn{2}{|l|}{} \\
& n & n & \multicolumn{2}{l|}{$\%$} \\
\hline Primary & 42 & 53.8 & 36 & 46.2 & 78 & 11.6 \\
\hline Secondary & 31 & 14.5 & 183 & 85.5 & 214 & 32.3 \\
\hline Higher & 78 & 21.1 & 292 & 78.9 & 370 & 56.1 \\
\hline Total & 151 & 22.8 & 511 & 77.2 & 662 & 100 \\
\hline
\end{tabular}

From the study of occupation of mothers of the investigated children it was evident that the children of servicewomen were around four times more exposed compared to the children of other mothers $\left[0 . R=3.79, \chi^{2}=35.199, p-\right.$ value $=0.000$, Table 7$]$.

Table 7. Distribution of children and adolescents according to their mothers' occupation and prevalence of diabetes

\begin{tabular}{|c|c|c|c|c|c|c|}
\hline \multirow{3}{*}{$\begin{array}{l}\text { Mother's } \\
\text { Occupation } \\
\text { Business }\end{array}$} & \multicolumn{4}{|c|}{ Prevalence of diabetes } & \multirow{2}{*}{\multicolumn{2}{|c|}{$\begin{array}{l}\text { Total } \\
\text { n } \%\end{array}$}} \\
\hline & \multicolumn{2}{|c|}{\begin{tabular}{|ll} 
Yes & \\
n & $\%$
\end{tabular}} & \multicolumn{2}{|c|}{$\begin{array}{ll}\text { No } & \\
n & \%\end{array}$} & & \\
\hline & 0 & 0.0 & 1 & 100.0 & 6 & 0.1 \\
\hline Service & 39 & 47.6 & 43 & 52.4 & 81 & 12.3 \\
\hline House wife & 112 & 19.3 & 468 & 80.7 & 575 & 87.6 \\
\hline Total & 151 & 22.8 & 511 & 77.2 & 662 & 100 \\
\hline
\end{tabular}

The higher rate of prevalence of diabetes were observed among the children and adolescent of families of lower income group and the differences in the proportions of prevalence rate were significant $\left[\chi^{2}=40.568, p-\right.$ value $=0.000$, Table 8]. The children of thefamilies of lower income group were around more than two times [O.R. $=2.29]$ exposed to prevalence of diabetes compared to the children of other types of families. 
Canonical Correlation Analysis to Study the Impacts of Different Social Factors on Level of BMI and Prevalence of Diabetes Among Children and Adolescents of Some Affluent Families

Table 8. Distribution of children and adolescents according to their family income and prevalence of diabetes

\begin{tabular}{|c|c|c|c|c|c|c|}
\hline \multirow{2}{*}{$\begin{array}{l}\text { Family } \\
\text { income (In } \\
\text { 000Tk) }\end{array}$} & \multicolumn{4}{|c|}{ Prevalence of diabetes } & \multicolumn{2}{|c|}{ Total } \\
\hline & $\begin{array}{l}\text { Yes } \\
\mathrm{n}\end{array}$ & $\%$ & $\begin{array}{l}\text { No } \\
\mathrm{n}\end{array}$ & $\%$ & $\mathrm{n}$ & $\%$ \\
\hline$<40$ & 67 & 34.0 & 130 & 66.0 & 197 & 29.8 \\
\hline $40-60$ & 18 & 26.5 & 50 & 73.5 & 68 & 10.4 \\
\hline $60-70$ & 42 & 29.2 & 102 & 70.8 & 144 & 22.2 \\
\hline $\begin{array}{l}70+ \\
\text { Total }\end{array}$ & $\begin{array}{l}24 \\
151\end{array}$ & $\begin{array}{l}9.5 \\
22.8\end{array}$ & $\begin{array}{l}229 \\
511\end{array}$ & $\begin{array}{l}90.5 \\
77.2\end{array}$ & $\begin{array}{l}253 \\
662\end{array}$ & $\begin{array}{l}37.3 \\
100.0\end{array}$ \\
\hline
\end{tabular}

It was noted that [ Table 9 ] majority ( $54.1 \%$ ) of the children and youth did not take nutritious food. But among them prevalence of diabetes was lower. Higher prevalence rate was noted among the children who took nutritious food. The proportions of prevalence of diabetes between two groups of children mentioned here were significant $\left[0 . R=2.38, \chi^{2}=21.41, R . R=\right.$ 1.95 , $\mathrm{p}$ - value $=0.000]$. The children who were taking nutritious food were more than two times exposed to prevalence of diabetes. Ninety five percent of them were in more risky condition compared to a group who did not take nutritious food.

Table 9. Distribution of children and adolescents according to taking of nutritious food and prevalence of diabetes.

\begin{tabular}{|c|c|c|c|c|c|c|}
\hline \multirow{2}{*}{$\begin{array}{l}\text { Taking } \\
\text { nutritious } \\
\text { food }\end{array}$} & \multicolumn{4}{|c|}{ Prevalence of diabetes } & \multirow{2}{*}{\multicolumn{2}{|c|}{$\begin{array}{l}\text { Total } \\
\text { n } \%\end{array}$}} \\
\hline & \multicolumn{2}{|c|}{$\begin{array}{l}\text { Yes } \\
\mathrm{n} \quad \%\end{array}$} & \multicolumn{2}{|c|}{$\begin{array}{l}\text { No } \\
\mathrm{n} \quad \%\end{array}$} & & \\
\hline Yes & 94 & 31.0 & 209 & 69.0 & 303 & 45.8 \\
\hline No & 56 & 15.6 & 302 & 84.4 & 358 & 54.1 \\
\hline No com & 1 & 100.0 & 0 & 0.0 & 1 & 0.1 \\
\hline Total & 151 & 22.8 & 511 & 77.2 & 662 & 100 \\
\hline
\end{tabular}

Table 10. Distribution of children and adolescents according to their food habit and prevalence of diabetes.

\begin{tabular}{|c|c|c|c|c|c|c|}
\hline \multirow{3}{*}{$\begin{array}{l}\text { Type of } \\
\text { food takes }\end{array}$} & \multicolumn{4}{|c|}{ Prevalence of diabetes } & \multicolumn{2}{|c|}{ Total } \\
\hline & \multicolumn{2}{|l|}{ Yes } & \multicolumn{2}{|l|}{ No } & & \\
\hline & $\mathrm{n}$ & $\%$ & $\mathrm{n}$ & $\%$ & & 0 \\
\hline More rice & 17 & 21.8 & 61 & 78.2 & 78 & 11.8 \\
\hline $\begin{array}{l}\text { More fish } \\
\text { and meat }\end{array}$ & 36 & 13.5 & 231 & 86.5 & 267 & 44.9 \\
\hline $\begin{array}{l}\text { Restaurant } \\
\text { food }\end{array}$ & 98 & 30.9 & 219 & 69.1 & 317 & 42.9 \\
\hline Total & 151 & 22.8 & 511 & 77.2 & 662 & 100 \\
\hline
\end{tabular}

It was observed that majority of the respondents were taking more fish and meat but [ Table 10 ] the prevalence of diabetes was less among them compared to other groups. A very big ( $42.9 \%$ ) group of children and youth were habituated in taking restaurant food and higher proportion of them $(30.9 \%)$ were affected by diabetes. Food habit was significantly associated with prevalence of diabetes[ $0 . R=2.46, \chi^{2}=25.07$, $\mathrm{p}$-value $=0.000]$. The O.R indicated that those who took restaurant food they were exposed more than two times to prevalence of diabetes.

Table 11. Distribution of children and adolescents according to utilization of time and prevalence of diabetes

\begin{tabular}{|c|c|c|c|c|c|c|}
\hline \multirow[b]{2}{*}{$\begin{array}{l}\text { Utilization } \\
\text { of time }\end{array}$} & \multicolumn{4}{|c|}{ Prevalence of diabetes } & \multicolumn{2}{|c|}{ Total } \\
\hline & $\begin{array}{l}\text { Yes } \\
\mathrm{n}\end{array}$ & $\%$ & \begin{tabular}{|l|} 
No \\
$\mathrm{n}$
\end{tabular} & $\%$ & $n$ & $\%$ \\
\hline Study & 12 & 10.7 & 100 & 89.3 & 112 & 16.9 \\
\hline $\begin{array}{l}\text { Watching } \\
\text { T.V }\end{array}$ & 83 & 31.4 & 181 & 68.6 & 264 & 39.9 \\
\hline Sleeping & 39 & 35.1 & 72 & 64.9 & 111 & 16.8 \\
\hline Others & 17 & 9.7 & 158 & 90.9 & 175 & 26.4 \\
\hline Total & 151 & 22.8 & 511 & 77.2 & 662 & 100.0 \\
\hline
\end{tabular}

It was observed that majority ( $39.9 \%$, Table11) of the investigated respondents spent their time by watching television and 31.4 percent of them were affected by diabetes. A lower proportionof respondents (16.8\%) slept after or before their academic activities and 35.1 percent of of them were affected by diabetes. Onefourth ( $26.4 \%$, Table 11 ) of the investigated children mentioned that they were involved in some other activities including games and sports. These group of children was mostly living in city center $(72.5 \%)$ and they had enough scope to be involved in physical activity like games and sports. Still they did not avail the scope of physical activities and due to that the proportions of prevalence of diabetes for different groups according to their utilization of time were significantly different $\left[\chi^{2}=10.63\right.$, $p$-value $=0.01,0 . R .=$ 0.28 ]. The result of odd ratio in favor of respondents involved in games and sports indicated they had the lower chance to be affected by diabetes.

It was observed that the different socioeconomic variables of the children and youth and their parents were significantly associated with prevalence of diabetes of them. Again, it was observed that 
Canonical Correlation Analysis to Study the Impacts of Different Social Factors on Level of BMI and Prevalence of Diabetes Among Children and Adolescents of Some Affluent Families

prevalence of diabetes and level of obesity were significantly associated. Hence, it was expected that level of obesity was associated with different social characters of the parents and offspring. Let us now investigate the association of those characters.

It was already noted that 70.2 percent of the investigated children and youth were in underweight group and 9.1 percent were obese and severely obese. Majority [Table 12, 78.2\%] of them were in the age group 10 years and above and among them 72.6 percent were in underweight group. In this group obese and severe obese children were 6.9 percent. Major obese and severe obese children (19.4\%) were among the children of age 5 to less than 10 years. The differences in the proportions of levels of obesity according to different age groups were significant $\left[\chi^{2}=39.043, p\right.$ - value $\left.=0.000\right]$. The prevalence of obesity and severe obesity among the children of age group 5 to less than 10 years compared to children of other age groups were too high [ $0 . \mathrm{R}=13.06$ ].

Now, let us investigate the reason of obesity and severe obesity among the children and youth. Some of the social factors might have enhanced the level of obesity. This was noted from the study of association of different factors and level of obesity

Table 12. Distribution of children and youth according to their age and level of obesity

\begin{tabular}{|c|c|c|c|c|c|c|c|c|}
\hline \multirow{3}{*}{ Level of obesity } & \multicolumn{5}{|c|}{ Age group ( in years) } & \multicolumn{3}{|l|}{ Total } \\
\hline & \multicolumn{2}{|l|}{$<5$} & \multicolumn{2}{|c|}{$5-10$} & \multicolumn{2}{|c|}{$10^{+}$} & \multirow[b]{2}{*}{$\mathrm{N}$} & \multirow[b]{2}{*}{$\%$} \\
\hline & $\mathrm{N}$ & $\%$ & $\mathrm{n}$. & $\%$ & $\mathrm{n}$ & $\%$ & & \\
\hline Underweight & 26 & 61.9 & 64 & 62.1 & 375 & 72.5 & 465 & 70.2 \\
\hline Overweight & 12 & 28.6 & 19 & 18.4 & 106 & 20.5 & 137 & 20.7 \\
\hline \multirow[t]{2}{*}{ Obese } & 1 & 2.4 & 9 & 8.7 & 32 & 6.2 & 42 & 6.3 \\
\hline & 3 & 7.1 & 11 & 10.8 & 4 & 0.8 & 18 & 2.8 \\
\hline Total & 42 & 6.3 & 103 & 15.6 & 517 & 78.1 & 662 & 100 \\
\hline
\end{tabular}

The investigated children and youth were classified into three classes by their age levels. These three groups of children were again classified by their level of obesity. The classified results were shown in Table 12. It was seen that $72.5 \%$ children and youth of the age group 10 years and above were underweight. The proportions of underweight children of other two age groups were lesser than the percentages of overall underweight group of children. The children less than 5 years of age had the highest percentage of the overweight group and this group of children had the 58 percent [O.R.=1.58] more chance of overweight compared to other groups of children. This differential in proportions of level of obesity according to age groups was highly significant $\left[\chi^{2}=38.94\right.$, $p$-value $\left.=0.000\right]$.

Table13. Distribution of children according to their gender and level of obesity

\begin{tabular}{|c|c|c|c|c|c|c|c|c|c|c|}
\hline \multirow[t]{3}{*}{ Sex } & \multicolumn{6}{|c|}{ Level of obesity } & & & \multicolumn{2}{|c|}{ Total } \\
\hline & \multicolumn{2}{|c|}{ Underweight } & \multicolumn{2}{|c|}{ Overweight } & \multicolumn{2}{|c|}{ Obese } & \multicolumn{2}{|c|}{ Sever obesity } & \multirow[t]{2}{*}{ No. } & \multirow[t]{2}{*}{$\%$} \\
\hline & $\mathrm{N}$ & $\%$ & $\mathrm{n}$ & $\%$ & $\mathrm{n}$ & $\%$ & $\mathrm{~N}$ & $\%$ & & \\
\hline Male & 298 & 77.4 & 46 & 11.9 & 28 & 7.3 & 13 & 3.4 & 385 & 58.2 \\
\hline Female & 167 & 60.3 & 91 & 32.8 & 14 & 5.1 & 5 & 1.8 & 277 & 41.8 \\
\hline Total & 465 & 70.2 & 137 & 20.7 & 42 & 6.3 & 18 & 2.8 & 662 & \\
\hline
\end{tabular}

Amongst the studied children 58.2 percent were males [Table 13] and 77.4 percent of them were underweight. The corresponding figure among females is 60.3 percent. The differential in obesity by sex differences is significant $\left[\chi^{2}=44.03\right.$, $p$-value $\left.=0.00\right]$.

The information of $72.5 \%$ children were reported from urban area. The corresponding percentages

of rural and semi-urban children were 18 and 9.5 . The classified information of number of children of different levels of obesity belonging to different residential areas were presented in Table 14. It was seen that maximum village children ( $76.5 \%$ ) were underweight compared to urban and semi-urban children. Again, among the village children, number of 
Canonical Correlation Analysis to Study the Impacts of Different Social Factors on Level of BMI and Prevalence of Diabetes Among Children and Adolescents of Some Affluent Families

obese and severe obese groups were lower compared children were significantly different $\left[\chi^{2}=12.45\right.$, to other groups of children. The difference in $p$-value= 0.04]. Similar findings were observed in proportions of level of obesity and residence of other studies [35, 36]

Table 14. Distribution of children according to their residence and level of obesity

\begin{tabular}{|l|c|c|c|c|c|c|c|c|}
\hline \multirow{2}{*}{ Level of obesity } & \multicolumn{4}{|c|}{ Residence } & \multicolumn{2}{c|}{ Total } \\
\cline { 2 - 10 } & \multicolumn{2}{|c|}{ Urban } & \multicolumn{2}{c|}{ Rural } & \multicolumn{2}{c|}{ Semi-urban } & \multirow{2}{*}{ No } & \multirow{2}{*}{$\%$} \\
\cline { 2 - 10 } & No. & $\%$ & No. & $\%$ & No. & $\%$ & & \\
\hline Underweight & 341 & 71.0 & 91 & 76.5 & 33 & 52.4 & 465 & 70.2 \\
\hline Overweight & 97 & 20.2 & 18 & 15.1 & 22 & 34.9 & 137 & 20.7 \\
\hline Obese & 29 & 6.0 & 7 & 5.9 & 6 & 9.5 & 42 & 6.3 \\
\hline Severe obesity & 13 & 2.8 & 3 & 2.5 & 2 & 3.2 & 18 & 2.8 \\
\hline Total & 480 & 72.5 & 119 & 18 & 63 & 9.5 & 662 & 100 \\
\hline
\end{tabular}

It was already mentioned that the study group of involved in some other activities including games children were mostly living in city center $(72.5 \%)$ and though they had the enough scope to be involved in physical activities like games and sports, still majority of the children (39.9\%) passed their time by watching television and $16.8 \%$ slept after or before their academic activities. One-fourth (26.4\%) of the investigated children mentioned that they were and sports [Table 15]. Around 72\% severeobese group killed their time by watching television. The corresponding percentage among obese group is 45.2. The differentials in proportions of utilization of time by the children of different obese groups were significantly different as $\left[\chi^{2}=54.12\right.$ with $\mathrm{p}$-value $=$ 0.00].

Table 15. Distribution of children according to their utilization of time and level of obesity

\begin{tabular}{|c|c|c|c|c|c|c|c|c|c|c|}
\hline \multirow{3}{*}{$\begin{array}{l}\text { Level of } \\
\text { obesity }\end{array}$} & \multicolumn{8}{|c|}{ Utilization of time } & \multicolumn{2}{|l|}{ Total } \\
\hline & \multicolumn{2}{|l|}{ Study } & \multicolumn{2}{|c|}{ Watch T.V. } & \multicolumn{2}{|l|}{ Sleep } & \multicolumn{2}{|c|}{ Others } & \multirow{2}{*}{ No } & \multirow{2}{*}{$\%$} \\
\hline & No. & $\%$ & No. & $\%$ & No. & $\%$ & No & $\%$ & & \\
\hline Underweight & 72 & 64.3 & 144 & 65.9 & 98 & 88.3 & 121 & 69.1 & 465 & 70.2 \\
\hline Overweight & 34 & 30.4 & 58 & 22 & 7 & 6.3 & 38 & 21.7 & 137 & 20.7 \\
\hline Obese & 4 & 3.6 & 19 & 7.2 & 3 & 2.7 & 16 & 9.2 & 42 & 6.3 \\
\hline Severe obesity & 2 & 1.7 & 13 & 4.9 & 3 & 2.7 & 0 & 0 & 18 & 2.8 \\
\hline Total & 112 & 16.9 & 264 & 39.9 & 111 & 16.8 & 175 & 26.4 & 662 & 100 \\
\hline
\end{tabular}

Let us now observe the food habit of investigated children and adolescent. As the investigating units were mostly from affluent city residence, they had the scope to get sufficient foods, with proper hygienic measures.. Among the investigating units $47.9 \%$ are habituated in taking food from restaurants. Among the obese children $54.7 \%$ are habituated in taking restaurant food [ Table 16]. In a separate study [37] it was reported that the increasing trend of obesity was associated with fast food from restaurant.

Table 16. Distribution of children and adolescents according to their food habit and level of obesity

\begin{tabular}{|c|c|c|c|c|c|c|c|c|}
\hline \multirow{3}{*}{ Level of obesity } & \multicolumn{4}{|c|}{ Food habit } & \multicolumn{4}{|c|}{ Total } \\
\hline & \multicolumn{2}{|c|}{ Much more rice } & \multicolumn{2}{|c|}{ More rice/fish\& meat } & \multicolumn{2}{|c|}{ Restaurant food } & \multirow{2}{*}{ No } & \multirow{2}{*}{$\%$} \\
\hline & No. & $\%$ & No. & $\%$ & No. & $\%$ & & \\
\hline Underweight & 56 & 12 & 191 & 41.1 & 218 & 46.9 & 465 & 70.2 \\
\hline Overweight & 14 & 10.2 & 50 & 36.5 & 73 & 53.3 & 137 & 20.7 \\
\hline Obese & 6 & 14.3 & 13 & 31 & 23 & 54.7 & 42 & 6.3 \\
\hline Severe obesity & 2 & 11.1 & 13 & 72.2 & 3 & 16.7 & 18 & 2.8 \\
\hline Total & 78 & 11.8 & 267 & 40.3 & 317 & 47.9 & 662 & 100 \\
\hline
\end{tabular}


Canonical Correlation Analysis to Study the Impacts of Different Social Factors on Level of BMI and Prevalence of Diabetes Among Children and Adolescents of Some Affluent Families

Of course, higher proportions of underweight (46.9\%) and overweight group of children (53.3\%) were habituated in taking restaurant food. However, the differentials in proportions of children taking restaurant food according to different levels of obesity were significant $\left[\chi^{2}=94.63\right.$ with $\mathrm{p}$-value $=$ 0.00]. Usually the children of affluent families were more likely to be stay back in the house and kill time by watching television. These children also had more chances to frequently visit fast food shops. Their parents could afford the cost of fast foods and they were also fulfilled the demand of their children if they had sufficient family income. It was observed that the monthly family income of $38.2 \%$ families was 70 thousand and above taka [Bangladesh currency] but $79.1 \%$ children of these families were in underweight group [Table 17].

Table 17. Distribution of children and adolescents according to their level of obesity and monthly income

\begin{tabular}{|c|c|c|c|c|c|c|c|c|c|c|}
\hline \multirow{3}{*}{ Level of obesity } & \multicolumn{8}{|c|}{ Monthly family income (in 000 taka) } & \multicolumn{2}{|c|}{ Total } \\
\hline & \multicolumn{2}{|l|}{$<40$} & \multicolumn{2}{|c|}{$40-60$} & \multicolumn{2}{|c|}{$60-70$} & \multicolumn{2}{|l|}{$70^{+}$} & \multirow{2}{*}{ No } & \multirow{2}{*}{$\%$} \\
\hline & No. & $\%$ & No. & $\%$ & No. & $\%$ & No & $\%$ & & \\
\hline Underweight & 107 & 54.3 & 40 & 58.8 & 118 & 81.9 & 200 & 79.1 & 465 & 70.24 \\
\hline Overweight & 62 & 31.5 & 13 & 19.1 & 15 & 10.4 & 47 & 18.6 & 137 & 20.69 \\
\hline Obese & 24 & 12.2 & 3 & 4.4 & 11 & 7.7 & 4 & 1.6 & 42 & 6.3 \\
\hline Severe obesity & 4 & 2 & 12 & 17.7 & 0 & 0 & 2 & 0.7 & 18 & 2.72 \\
\hline Total & 197 & 29.8 & 68 & 10.2 & 144 & 21.8 & 253 & 38.2 & 662 & 100 \\
\hline
\end{tabular}

It was seen that prevalence of obesity was higher among the children of low income group of families. This differential in observing obesity was significantly different among the low income group of families $\left[\chi^{2}=53.06\right.$ with $\mathrm{p}$-value $\left.=0.00\right]$.

Family environment was one of the correlates of obesity among children [19]. It seemed that family environment was influenced by parents' education and occupation. Let us investigate how fathers' and mothers' education were associated with children and adolescents obesity. It was seen that [Table 18] the fathers of $77.9 \%$ children were higher educated and $75 \%$ children of them were underweight. The percentage of illiterate fathers was 3.5 and 91\% children of these fathers were underweight. But obesity and severe obesity among children of illiterate and primary educated fathers were more (8.7 and $17.4 \%$ respectively) compared to the children of secondary educated $(2.1 \%)$ fathers. The differential in proportions of level of obesity and fathers' educational level were highly significant $\left[\chi^{2}=111.70\right.$ with $p$-value $=0.00]$. Similar significant differentials in proportions of obesity of children according to the differences of mothers' education were also observed [Table 19, $\chi^{2}=39.23$ with $\mathrm{p}$-value $\left.=0.00\right]$.

Table 18. Distribution of children and adolescents according to their level of obesity and their father's education

\begin{tabular}{|c|c|c|c|c|c|c|c|c|c|c|}
\hline \multirow{3}{*}{ Level of obesity } & \multicolumn{6}{|c|}{ Father's education } & & \multicolumn{3}{|c|}{ Total } \\
\hline & \multicolumn{2}{|c|}{ Illiterate } & \multicolumn{2}{|c|}{ Primary } & \multicolumn{2}{|c|}{ Secondary } & \multicolumn{2}{|c|}{ Higher } & \multirow{2}{*}{ No } & \multirow{2}{*}{$\%$} \\
\hline & No. & $\%$ & No. & $\%$ & No. & $\%$ & No & $\%$ & & \\
\hline Underweight & 21 & 91.3 & 17 & 73.9 & 40 & 40 & 387 & 75 & 465 & 70.2 \\
\hline Overweight & - & - & 2 & 8.7 & 56 & 56 & 78 & 15 & 137 & 20.7 \\
\hline Obese & - & - & 4 & 17.4 & 2 & 2 & 36 & 7 & 42 & 6.3 \\
\hline Severe obesity & 2 & 8.7 & - & & 2 & 2 & 15 & 2.9 & 18 & 2.8 \\
\hline Total & 23 & 3.5 & 23 & 3.5 & 100 & 15.1 & 516 & 77.9 & 662 & 100 \\
\hline
\end{tabular}


Canonical Correlation Analysis to Study the Impacts of Different Social Factors on Level of BMI and Prevalence of Diabetes Among Children and Adolescents of Some Affluent Families

Table 19. Distribution of children and adolescents according to their level of obesity and level of mother's education

\begin{tabular}{|c|c|c|c|c|c|c|c|c|c|c|}
\hline \multirow{3}{*}{ Level of obesity } & \multicolumn{6}{|c|}{ Mother's education } & & \multicolumn{3}{|l|}{ Total } \\
\hline & \multicolumn{2}{|c|}{ Illiterate } & \multicolumn{2}{|c|}{ Primary } & \multicolumn{2}{|c|}{ Secondary } & \multicolumn{2}{|c|}{ Higher } & \multirow{2}{*}{ No } & \multirow{2}{*}{$\%$} \\
\hline & No. & $\%$ & No. & $\%$ & No. & $\%$ & No & $\%$ & & \\
\hline Underweight & 34 & 87.2 & 28 & 71.8 & 140 & 65.4 & 263 & 71.1 & 465 & 70.2 \\
\hline Overweight & 1 & 2.6 & 8 & 20.5 & 65 & 30.4 & 63 & 17 & 137 & 20.7 \\
\hline Obese & 2 & 5.1 & 3 & 7.7 & 6 & 2.8 & 31 & 8.4 & 42 & 6.3 \\
\hline Severe obesity & 2 & 5.1 & - & - & 3 & 1.4 & 13 & 3.5 & 18 & 2.8 \\
\hline Total & 39 & 5.9 & 39 & 5.9 & 214 & 32.3 & 370 & 55.9 & 662 & 100 \\
\hline
\end{tabular}

Significant differences in the level of obesity according to the variations in the levels of occupation of fathers [Table 20] were also observed $\left[\chi^{2}=186.02\right.$ with $p$-value $\quad$ [Table $21, \chi^{2}=10.50$ with $p$-value $\left.=0.572\right]$.

Table 20. Distribution of children and adolescents according to their level of obesity and levels of father's occupation

\begin{tabular}{|l|c|c|c|c|c|c|c|c|c|c|}
\hline \multirow{3}{*}{ Level of obesity } & \multicolumn{4}{|c|}{ Father's occupation } & \multicolumn{4}{|c|}{ Total } \\
\cline { 2 - 12 } & \multicolumn{2}{|c|}{ Agriculture } & \multicolumn{2}{|c|}{ Business } & \multicolumn{2}{|c|}{ Service } & \multicolumn{2}{|c|}{ Others } & \multirow{2}{*}{$\%$} \\
\cline { 2 - 12 } & No. & $\%$ & No. & $\%$ & No. & $\%$ & No & $\%$ & & \\
\hline Underweight & 27 & 79.4 & 165 & 55.9 & 253 & 85.8 & 20 & 52.6 & 465 & 70.2 \\
\hline Overweight & 2 & 5.9 & 100 & 33.9 & 31 & 10.5 & 4 & 10.5 & 137 & 20.7 \\
\hline Obese & 3 & 8.8 & 27 & 9.2 & 9 & 3 & 3 & 7.9 & 42 & 6.3 \\
\hline Severe obesity & 2 & 5.9 & 3 & 1 & 2 & 0.7 & 11 & 29 & 18 & 2.8 \\
\hline Total & 34 & 5.1 & 295 & 44.6 & 295 & 44.6 & 38 & 5.7 & 662 & 100 \\
\hline
\end{tabular}

Table 21. Distribution of children according to their level of obesity and level of mother's occupation

\begin{tabular}{|l|c|c|c|c|c|c|c|c|}
\hline \multirow{3}{*}{ Level of obesity } & \multicolumn{9}{|c|}{ Mother's occupation } & \multicolumn{2}{l|}{ Total } \\
\cline { 2 - 10 } & Housewife & \multicolumn{2}{|l|}{ Service } & \multicolumn{2}{l|}{ Others } & \multirow{2}{*}{$\%$} \\
\cline { 2 - 10 } & No. & $\%$ & No. & $\%$ & No. & $\%$ & & \\
\hline Underweight & 396 & 68.9 & 65 & 80.2 & 4 & 66.7 & 465 & 70.2 \\
\hline Overweight & 123 & 21.4 & 12 & 14.8 & 2 & 33.3 & 137 & 20.7 \\
\hline Obese & 40 & 7 & 2 & 2.5 & 0 & 0 & 42 & 6.3 \\
\hline Severe obesity & 16 & 2.7 & 2 & 2.5 & 0 & 0 & 18 & 2.8 \\
\hline Total & 575 & 86.9 & 81 & 12.2 & 6 & 0.9 & 662 & 100 \\
\hline
\end{tabular}

\section{Canonical Correlation Analysis}

It was seen that some of the socioeconomic variables were associated with prevalence of diabetes and level of obesity. Again, prevalence of diabetes and level of obesity were significantly associated. Thus to study the complex relationship of socioeconomic variables with prevalence of diabetes habit and level of obesitycanonical correlation analysis was performed. The analysis was done by transforming some of the variables in nominal scale.
In performing the canonical correlation analysis the following information were observed. Here $R_{x x}$ is the correlation matrix [Table 22] of the predictor variables, $R_{x y}$ [Table23] is the correlation matrix of the criterion and predictor variables and $R_{y y}$ is the correlation matrx [Table24] of the criterion variables. The rank of the product matrix $\mathrm{R}_{x \mathrm{x}}{ }^{-1} \mathrm{R}_{\mathrm{xy}} \mathrm{R}_{\mathrm{yy}}{ }^{-1} \mathrm{R}$ or $\mathrm{R}_{\mathrm{yy}}$ ' ${ }^{1} R_{y x} R_{x x}{ }^{-1} R_{x y}$ is $M=\min (p, q)=2$ and hence there would be at best 2 canonical variate pairs. 
Canonical Correlation Analysis to Study the Impacts of Different Social Factors on Level of BMI and Prevalence of Diabetes Among Children and Adolescents of Some Affluent Families

Table 22. Correlation matrix for the variables in the predictor set (X-set), $R_{x x}$

\begin{tabular}{|c|c|c|c|c|c|c|c|c|c|}
\hline Residence $\left(\mathrm{x}_{1}\right)$ & 1 & & & & & & & & \\
\hline Father's education $\left(\mathrm{x}_{2}\right)$ & -0.165 & 1 & & & & & & & \\
\hline Mother's education $\left(\mathrm{x}_{3}\right)$ & -0.168 & 0.722 & 1 & & & & & & \\
\hline Father's occupation $\left(\mathrm{x}_{4}\right)$ & -0.106 & 0.417 & 0.387 & 1 & & & & & \\
\hline $\begin{array}{l}\text { Mother's occupation } \\
\left(\mathrm{x}_{5}\right)\end{array}$ & -0.067 & 0.159 & 0.129 & 0.154 & 1 & & & & \\
\hline Family income $\left(\mathrm{x}_{6}\right)$ & -0.235 & 0.282 & 0.259 & 0.158 & 0.208 & 1 & & & \\
\hline Food habit $\left(\mathrm{x}_{7}\right)$ & -0.025 & 0.144 & 0.213 & 0.296 & 0.123 & 0.027 & 1 & & \\
\hline Time utilization $\left(\mathrm{x}_{8}\right)$ & 0.014 & -0.003 & -0.094 & -0.185 & 0.074 & -0.138 & -0.140 & 1 & \\
\hline Age $\left(x_{9}\right)$ & 0.057 & 0.057 & -0.072 & -0.012 & 0.04 & 0.210 & 0.034 & 0.003 & 1 \\
\hline
\end{tabular}

Table 23. Correlation matrix for the variables in $X$-set and Y-set: $R_{x y}$

\begin{tabular}{|l|c|c|}
\hline & BMI $\left(\mathrm{y}_{1}\right)$ & Prevalence of diabetes $\left(\mathrm{y}_{2}\right)$ \\
\hline Residence $\left(\mathrm{x}_{1}\right)$ & -0.095 & 0.013 \\
\hline Father's education $\left(\mathrm{x}_{2}\right)$ & 0.087 & -0.039 \\
\hline Mother's education $\left(\mathrm{x}_{3}\right)$ & 0.155 & 0.011 \\
\hline Father's occupation $\left(\mathrm{x}_{4}\right)$ & -0.048 & 0.100 \\
\hline Mother's occupation $\left(\mathrm{x}_{5}\right)$ & -0.077 & -0.065 \\
\hline Family income $\left(\mathrm{x}_{6}\right)$ & -0.022 & -0.150 \\
\hline Food habit $\left(\mathrm{x}_{7}\right)$ & -0.036 & 0.052 \\
\hline Utilization of time $\left(\mathrm{x}_{8}\right)$ & 0.013 & -0.069 \\
\hline Age $\left(\mathrm{x}_{9}\right)$ & -0.046 & -0.046 \\
\hline
\end{tabular}

Table 24. Correlation coefficient matrix for the variables in $Y$-set, $R_{y y}$

\begin{tabular}{|l|c|c|}
\hline BMI & 1 & \\
\hline Prevalence of diabetes & 0.073 & 1 \\
\hline
\end{tabular}

Table 25. Results related to test of significance of canonical variatepairs:

\begin{tabular}{|l|l|l|l|l|l|l|}
\hline $\begin{array}{c}\text { Canonical } \\
\text { variate pair }\end{array}$ & Eigen values & Wilk's $\Lambda$ & F-statistics & P-value & $\begin{array}{c}\text { Canonical correlation } \\
\text { coefficients }\end{array}$ & $\begin{array}{c}\text { \% of the variation } \\
\text { explained }\end{array}$ \\
\hline 1 & 0.093 & 0.857 & 4.746 & .000 & 0.305 & 62.82 \\
\hline 2 & 0.055 & 0.945 & 3.779 & .000 & 0.235 & 37.18 \\
\hline
\end{tabular}

There would be at best 2 canonical variate pairs. The The canonical weights were the elements of eigen vectors variate pairs are related to the eigen values $\lambda_{1}=0.093$ corresponding to $\lambda_{1}$ and $\lambda_{2}$ and these weights indicated the and $\lambda_{2}=0.055$ and both pairs are found significant importance of the variables to maximize the correlations [Table25] of two sets. The weights were shown in Table 26. 
Canonical Correlation Analysis to Study the Impacts of Different Social Factors on Level of BMI and Prevalence of Diabetes Among Children and Adolescents of Some Affluent Families

Table 26. Standardized canonical correlation coefficients for X-set and Y-set:

\begin{tabular}{|c|c|c|c|c|}
\hline \multirow{2}{*}{ Variables } & \multicolumn{2}{|c|}{ X-set } & \multicolumn{2}{c|}{ Y-set } \\
\cline { 2 - 5 } & $\lambda 1$ & $\lambda 2$ & $\lambda 1$ & $\lambda 2$ \\
\hline $\mathrm{x}_{1}$ & 0.335 & 0.004 & & \\
\hline $\mathrm{x}_{2}$ & -0.014 & -0.364 & & \\
\hline $\mathrm{x}_{3}$ & -0.713 & 0.091 & & \\
\hline $\mathrm{x}_{4}$ & 0.319 & 0.690 & & \\
\hline $\mathrm{x}_{5}$ & 0.303 & -0.140 & & \\
\hline $\mathrm{x}_{6}$ & 0.339 & -0.648 & & \\
\hline $\mathrm{x}_{7}$ & -0.085 & 0.031 & & \\
\hline $\mathrm{x}_{8}$ & -0.079 & -0.214 & & \\
\hline $\mathrm{x}_{9}$ & -0.514 & -0.128 & & -.0 .153 \\
\hline $\mathrm{y}_{1}$ & & & -0.995 & 1.000 \\
\hline $\mathrm{y}_{2}$ & & & -0.036 & \\
\hline
\end{tabular}

It was observed that the first canonical variate pair explained $62.82 \%$ of variation in the data set and the important variables to explain this variation were father's education followed by age of children. The variable fathers' education was significantly associated with both prevalence of diabetes [ Table 4] and level of obesity [ Table 18]. The second canonical variate pair explained37.18 \% of variation in the data set and the important variables to explain this variation were father's occupation followed by family income. From the correlation matrix [Table23] it was seen that the level of BMI was highly correlated with mothers' education and age of children. Family income and fathers' occupation were highly correlated with prevalence of diabetes.

\section{CONCLUSION}

The present study was conducted to observe the level of obesity and prevalence of diabetes among children and adolescents of some randomly selected families of the students of American International University - Bangladesh. Most of the families were city dwellers and these families were socially and economically in better position [28] compared to the general people of Bangladesh. However, the obesity and severe obesity among children were similar to that of the general people of the country. Obesity and severe obesity were associated with the parent's social and economic status. Again, prevalence of diabetes among the children and youth were significantly associated with the parent's socioeconomic characteristics and also with some of the characteristic of the children.
Thus it was decided to study the complex relationship of the level of obesity and prevalence of diabetes with other social characters. This objective was fulfilled by doing the canonical correlation analysis. The analysis indicated that father's education, occupation, family income and age of children and youth were the most important factors to influence simultaneously the level of obesity and prevalence of diabetes.

The study indicated that prevalence of diabetes was dependent on level of obesity and both these characteristics are the problem for both parents and health planners. Parents can take care of foods of their offspring and motivate to take home foods as per as possible avoiding the restaurant foods. They can motivate their kids to spend their time in doing some activities related to physical work in addition to their academic works. Government and school authority should introduce some regulations so that physical education is a compulsory co-curricular activity of the school. Parents can encourage their kids to avoid watching television and untimely sleeping. Some of the steps of parents can prevent the alarming increase in the rates of obesity and severe obesity and in the rate of prevalence of diabetes.

\section{REFERENCES}

[1] Haslam, D.W. and Jamesh W.P.T (2005): Obesity. Lancet 366, 1197-1209.

[2] de Dnis M, Blössner M, Borghi, E. (2010) Global Prevalence and Trends of Overweight andObesity among Preschool Children. Am. J. Cli. Nutrition,92,1257-64. 
Canonical Correlation Analysis to Study the Impacts of Different Social Factors on Level of BMI and Prevalence of Diabetes Among Children and Adolescents of Some Affluent Families

[3] Rahman. S, Islam MdTauhidul, and Dewan S Alam (2014): Obesity and Overweight in Bangladeshi Children and Adolescents: a scoping review, BMC Public Health ,14,70.

[4] Biswas,T; Islam,A; Islam Md.S; Pervin, $\mathrm{S}$ and Rawal, L.B.(2017): Overweight and obesity among children and adolescents in Bangladesh: a systematic review and meta- analysis, Public Health,142, 94-101.

[5] Anna MG, Sonia Caprio (2008) Obesity in children and adolescents, J. Clin, Endocrinol Metab.,93,(11 Suppl.1),531-536.

[6] Daniels, S. (2006): The consequence of childhood overweight and obesity, Future Child,16,47-67.

[7] Epstien, L.H., Raja, S., Daniel, T.O., et al (2012): The built environment moderates effects of family based childhood obesity treatment over 2 years. Ann. Behav. Med., 44, 248-258

[8] Freedman, D.S., Khan, L.K.,Serdula, M.K., Dietz, W.H.; Srinivasan, S.R., and Berenson, G.S.,(2005): Racial differences is the tracking of childhood BMI to adulthood Obes, Res.,13,928-935

[9] Harris, K., Gordon,-Larsen,P.; Chantala, K.,andUdry, R.(2006): Longitudinal trends inrace/ethnic disparities in trending health indicators from adolescents to young adulthood, Arch. Pediator., Addese, Med.,160,74-81.

[10] Serdula, M.K., Ivery, D., Coates, R.J.;Freedman, D.S.; Williamson, D. S., and Byres, T (1993): Do obese children become obese adults? A review of literature, Prev. Med-22,167-177.

[11] M. Lee, J.M., Okumura, M.J., Davis, M.M., Herman, W.H., and Gurney, J.G.(2006): Prevalence and determinantsof insulin resistance among U.S. adolescents, A Population Based Study. Diabets Care, 29, 2427-2432.

[12] Weiss, R., Taksali, S.E., TAmborlane, W.V.; Peterson, K.F., Bonadonna, R.C., Boselli, L.,Barbetta, G., Allen, K., Rife, F., SAvoye, M., Dziura, J., Sherwin, W., Shullman, G.I., and Caprio, S.(2003): Prediabetes in obese youth: a syndrome of impaired glucose tolerance, Severe insulin resistance, and altered myocellular and abdominal fat partitioning, Lancet, 362,951-957.
[13] Weiss, R., Taksali, S.E., Dutour,Ss., Yeckel, C.W., Papadentris, X., Cline, G., Tamborlane, W. V., Dzuira, J., Shulman, G.I., and Caprion, S(2005): The obese insulin-sensitive adolescent: importance of adiponectin and lipid partitioning, J.Clin. EndocrinolMetab., 90, 3731-3737.

[14] Pulgaron, E. R. (2013): Child obesity: a review of increased risk for physical and psychologicalcombordities, ClinTher, 35 A 18-A 32.

[15] Sinha, R, Fisch, G., Teague, B., Tamborlane W. V., Banyas, B, Allen, K., Savoye, M., Rieger, V., Taksali, S., Barbetta, G., Sherwin, R. S., and Caprio, S. (2002): Prevalence of impaired glucose tolerance among children and adolescents with marked obesity, N. Engl. J. Med.,346, 802-810

[16] Weiss, R., Dzuria, J., Burgert, T.S., et al (2014): Obesity and the metabolic syndrome in children and adolescents, N Engl. J. Med, 350, 2362-2374.

[17] Herva,Ai., Laitinem, J., Miettunen, J., Veijola, J., Kervonen, J. T., Laksy, et. Al (2006): Obesity and depression: results from the longitudinal Northern Finland 1966 birth cohort study, Int. J. Obes, 30,520-527.

[18] Strauss,R.S., Knigh, J.(1999): Influence of the home environment on the development of obesity in children, Pediatrices, 103, e85.

[19] Ray, J.W., Klesges, R.C.(1993): Influences on the eating behavior of the children, Ann. N.Y. Acad. Sci., 699,57-69.

[20] Neumark-Sztainer, D.,story, M., Resnick, M.D., Blum, R.W.(1996): Correlates of inadequate fruit and vegetable consumption among adolescents. Prev. Med., 25,497-505.

[21] Kennedy, E., Powell, R.(1997): Changing eating patterns of American children: a viewfrom 1996, J. Ann. Coll. Nutr. 16, 524-529.

[22] Bhargava, S.K., Sachadev, A.S., Fall, C.H., Osmond, C.,LAkshmy, R., Barker, D. J. et al (2004): Relation of serial changes in childhood body mass index to impaired glucose tolerance is young adulthood, N. Engl. J. Med., 350,865-875.

[23] Nixon, G.M., Thompson, J. M., Han D. Y.,Becroft, D.M., Clark, P.M., Robison,E. et al(2008): Short sleep duration in middle childhood risk factors and consequences, sleep,31 71-78. 
Canonical Correlation Analysis to Study the Impacts of Different Social Factors on Level of BMI and Prevalence of Diabetes Among Children and Adolescents of Some Affluent Families

[24] Manu Raj. And R. Krishna.Kumar(2010): Obesity in childhood and adolescents, Indian Jour. Med. Research, 32(5), 598-617.

[25] Lin,B.H., Guthrie, J., Frazao, E. editors(1999): Nutrient contribution of food away from home: America's eating habbits: changes and consequences, Economic Research Service Report,213-39, Agriculture Information Bulletin No. 750.

[26] Pereria, M.A., Kartashov, A.I., Ebbeling, C.B., Van Horn, L, Slattery, M.L., Jacobs, D.R. Jr. et al(2005): Fast food habits, weight gain, and insulin resistance: 15-years prospective analysis, Lancet, 365,36-42.

[27] Epstein,L.H., Saetens, B.E.(2000): Behavioral Economics of obesity: food intake and energy expenditure. In Bickel,

[28] Bhuyan, K.C. and Ghffar, F.A.,(1999) Canonical correlation analysis to study the influences of socioeconomic factors simultaneously on fertility and child mortality, Jour. Stat. Studies, 19, 7-15,

[29] Kabir, A., Merill, R.D., Shamim, A.A., Klemn, R.D.W., Labrique, A.B., Christain, P., West Jr., K.P. and Nasser, M.; (2014) Canonical correlation analysis of infant's size at birth and maternal factors: A study in rural north-west Bangladesh, 0094243, Jour. Pone.

[30] Hamid, J.S., Meaney, C., Crowcroft, N., Granerod, J. and Beyene, J.;(2011) Potential risk factors associated with human encephalitis: application of canonical correlation analysis; BMC, 11, 120,

[31] JannatulFardus and Bhuyan, K.C. (2016): Discriminating diabetic patients of some rural and urban areas of Bangladesh: A discriminant analysis approach, EuromediterreanBiom., Jour.11(9),134-140.

[32] Mahfuza, K. and Bhuyan,K.C.,(2014): Awareness of health hazard of tobacco consumption among students of American International UniversityBangladesh, AJSE; 13(1), 85-92.

[33] Hoque,M.E,Suhail,A.R.Doli,Munim,M, Kurt Long , Louis,W.N. andAbdullah,A.M (2014) : Prevalence of overweight and obesity among children and adolescents of the Indian subcontinent : A meta analysisapproach,Nutrition Review,77(8),542 - 550

[34] Bhuyan, K.C.(2004): Multivariate Analysis and its Applications, New Central BookAgency(p) Ltd.

[35] Rahman. S, Islam MdTauhidul, and Dewan S Alam (2014): Obesity and Overweight in Bangladeshi Children and Adolescents: a scoping review, BMC Public Health ,14,70.

[36] Chris Wool Stem(2017): Type 2 diabetes and kids, The growing Epidemic, Health Day.

[37] Currie, J., Della Vigna, S., Moretti, E. et al (2010): The effect of fast food restaurants on obesity and weight gain, Amer.Econ., Jour.,Economic Policy,2,32-63.

Citation: K.C. Bhuyan, A.F. Urmi. Canonical Correlation Analysis to Study the Impacts of Different Social Factors on Level of BMI and Prevalence of Diabetes Among Children and Adolescents of Some Affluent Families. Archives of Diabetes and Endocrine System. 2019; 2(1): 01-14.

Copyright: (C) 2019 K.C. Bhuyan, A.F. Urmi. This is an open access article distributed under the Creative Commons Attribution License, which permits unrestricted use, distribution, and reproduction in any medium, provided the original work is properly cited. 